\title{
On the Potential Factors Affecting Language Teachers' Selection of Communication Strategies in Intercultural Immersion Experience
}

\author{
Xiaohong Wei \\ School of Foreign Languages, Sichuan Normal University, Chengdu 610101, Sichuan, China \\ Email: 453699334@qq.com
}

Keywords: communication strategies; intercultural immersion experience; factors

\begin{abstract}
Much of the literature on communicative competence focuses on the importance in intercultural communication and the acquisition of communicative competence, among which strategic competence deserves a special place. Most of these studies focus on foreign/second language learners, but few centre on the teachers. Based on a qualitative study of nine Chinese language teachers as 4-month visiting scholars in America, this paper mainly examines the factors affecting language teachers' selection of communication strategies in intercultural immersion experience. The findings show that language proficiency, personality and group dynamics are the major factors for their choice of specific strategies in different contexts.
\end{abstract}

\section{Introduction}

With the acceleration of globalization and the continual socioeconomic development of China, more and more Chinese people gain chances to go abroad. Substantial immersion in the target language culture was proved to be important for highest second language proficiency. As for the teachers of English, complete immersion in the target culture is also a good way to improve their language proficiency and intercultural communicative competence. Due to the author's personal experience as a visiting scholar in the United States, she is interested in exploring what has affected language teachers' choice of communication strategies in different contexts. To sort out her thinking, she conducted this qualitative case study, which focused on 9 Chinese visiting scholars as a group in the United States.

\section{Literature Review}

"Communication strategies (CSs) may be seen as attempts to bridge the gap between the linguistic knowledge of the second-language learner and the linguistic knowledge of the target language interlocutor in real communication situations. Approximation, mime, and circumlocution may be used to bridge this gap. Message abandonment and avoidance may be used where the gap is perceived as unbridgeable".[1] With regard to the use of communication strategies in intercultural communication, some scholars hold that learners who emphasize the importance of using the language often utilize communication strategies. Bialystok comprehensively analyzes communication strategies for second-language use and factors affecting the selection of them in interpersonal communication from the psychological perspective, holding that communication strategies are used to overcome the gaps in our knowledge of a second language. [2] In China, scholars and researchers focus more on the exploration of the cultivation of Chinese language learners' strategic competence in communication. For example, some scholars carry out empirical researches into the status quo of Chinese foreign language learners' strategic competence, especially concentrating on their use of communication strategies, the factors influencing the selection of strategies, and then provide some practical ways for cultivation of language learners' strategic competence.[3]

In intercultural immersion environment, what factors affect language teachers' selection of 
strategies in different contexts? This paper intends to focus on Chinese language teachers as visiting scholars in America.

\section{Research Methodology}

The research was carried out in an American university of liberal arts. The 9 visiting scholars were all teachers of English from different universities of China. Four of them are females: Kate, Jessica, Erica, and Carol, while five of them are males: Ben, Lee, Ron, Martin and Andy (all names for persons and places are pseudonyms). The age of them ranges from 31 to 43 . They are classified into two groups: high-immersion group including Erica, Lee, Jessica, Ron and Andy who were comparatively more ambitious and active in language use; low-immersion group were Kate, Carol, Ben and Martin, who were relatively more reserved and less active in communication. The data gathered for this study included one semi-structured interview and field notes of participant observation.

\section{Findings and Discussion}

According to the author's previous study, though Chinese language teachers all intended to use communication strategies in their communication, the frequency of strategy use or the choice of strategies was different. Inevitably, the results of their intercultural immersion experience would also vary. Only two teachers thought they were completely immersed in the culture and their communicative competence had been improved ideally because they could take advantage of various communication strategies and communicative chances. The other seven language teachers regarded their experience as partial cultural immersion and their strategic competence was not improved as expected. So what caused their selection of communication strategies?

\subsection{Language Proficiency}

Language proficiency indeed influences language teachers' different selection of communication strategies. In intercultural communication, the strategies make different linguistic demands, and some may be too sophisticated for less advanced language learners. Many scholars such as Brown had found in their empirical studies that the language proficiency level of the speaker or linguistic factors on language learning, especially second language acquisition influenced language learners' selection of certain communication strategies to some extent. [4] Since language teachers are all English majors and have achieved their M.A. degrees, the author assumes that they may not have problems in language use. However, according to the interview and observation, due to the regional difference and the quality level of the universities, discrepancies in language proficiency did exist among language teachers. All of them had no difficulty in reading and writing, but difference occurred in listening and speaking. For example, Erica, Andy, Lee and Ben are from the large cities and universities where foreign teachers, overseas students and international tourists are frequented, and they have more opportunities to participate in intercultural communication. So they comment on their language proficiency as follows:

"I am confident in my listening and speaking." (Erica)

"I can communicate with foreigners in English very well". (Andy)

"My listening is very good. I can express myself quite well." (Lee)

"Good listening and fluent expression in class."(Ben)

While the other five language teachers have some problems in language proficiency,

"My listening and speaking are somewhat poor because I seldom have chances to communicate in English.”(Jessica)

"My listening is comparatively weak."(Martin)

"My vocabulary is not large enough, esp. about daily life."(Carol)

"My listening is just-so-so, and my speaking is poor."(Kate)

"Poor listening often makes me at a loss or just catch the main idea, thus my speaking is not so 
fluent." (Ron)

According to the observation, at the very beginning, those who have some problems in language proficiency tended to keep silent, or were more likely to choose avoidance strategy when they were not certain about the conversation topics, while those who are comparatively confident in their language proficiency managed to be in control of the say, thus circumlocution, approximation and non-linguistic signals were used quite often. With more familiarity with the environment and more motivation stimulated, all the language teachers would like to use more communication strategies, but differences still existed in the frequency of CSs use. Those who were confident in their language proficiency tended to try every means to grab the opportunities to communicate. At this time, some language teachers, whose language proficiency was not so good, but who had strong intention to communicate, managed to use more CSs to get themselves across. Jessica was a case in point. A professor stated, “Jessica's English is not so good as some of the others, but she works quite hard when she is talking to me. She tries many strategies, especially literal translation, explanation and body language to express herself clearly. So her conversation with me is sometimes a little bit stiff, not flowing. But she certainly makes communication well."

\subsection{Personality}

Personality plays an important role in language teachers' selection of communication strategies. Tarone suggested that certain personality characteristics might be associated with preferences for avoidance strategies or appeal for assistance strategies. [5] In recent thinking, there is no doubt at all about the importance of examining personality factors in building a theory of second language acquisition and in finding their effects on language learners' selection of learning and communication strategies. [4]

Through the observation and interview, the author finds that personality is closely related to the language teachers' choice of communication strategies in intercultural communication. A professor held during our interview, "Personality affects very much how we do with language. People who are extroverted or talk more are not afraid of making mistakes. They are generally willing to try, and they can develop better skills especially spoken one. They always keep trying. People who are more introverted may easily stop or even quit trying. If he can't say something correctly, he doesn't say anything." This is the case to many Chinese language teachers. For example, in classroom communication, low-immersion group tended to choose avoidance strategies while the high-immersion group preferred circumlocution and appeal for help at the very beginning. Different personalities produced different performances. In the latter part of the observation, though all the Chinese language teachers tended to use more proper strategies in their social and transactional communication, the frequency and communicative results of strategy use are different between the two groups. Generally speaking, in order to gain more opportunities to communicate, high-immersion group were more courageous and risky in using strategies. Thus the employment frequency of communication strategies among the high-immersion group is higher than that of the low-immersion group. Comparatively speaking, most of the high-immersion group members showed fluency and appropriateness in formal communication, which could be exemplified by the meeting of the university faculty with Chinese visiting scholars, where Erica, Andy and Ron, as the major representatives, communicated with the faculty successfully and profoundly. The low-immersion group could communicate freely at last, but due to the influence of personality, they lacked the initiative to start conversation, thus resulting in their lack of enough chance to communicate with the local people.

\subsection{Group Dynamics}

Group dynamics refers to a system of behaviors and psychological processes occurring within a social group (intragroup dynamics), or between social groups (intergroup dynamics). Based on their feelings and emotions, members of a group form a common perception. The interactive psychological relationship in which members of a group form this common perception is actually "Group Dynamics".[6] In this study, the author mainly deals with Intragroup dynamics--the underlying 
processes that give rise to a set of norms, roles, relations, and common goals that characterize a particular social group. Within a group, group cohesion is thought to be one of the most important characteristics, and has been linked to group performance, intergroup conflict and therapeutic change. Beliefs within the ingroup are based on how individuals in the group see their other members. Individuals tend to upgrade likeable in-group members and deviate from unlikeable group members, making them a separate out-group, which is called the black sheep effect. [7]Individual behavior is influenced by the presence of others.

There are both positive and negative implications of group influence on selection of communication strategies among the Chinese language teachers. On the one hand, as a large group who lived and studied together, the chance of speaking English at one time was limited, especially in classroom communication and when the group was communicating with one or two Americans. Those who felt that their English was better than others were always trying to use circumlocution and appeal for help to extend their speaking time. Also, they would like to create chances for themselves by many means to join in the native speakers' conversation so as to improve their communicative competence quickly. For example, in the interview with Erica, Andy and Lee, they commented positively on group influence,

"Group pressure makes me aggressive to grasp and create the chance to speak English."(Erica)

"I want to make progress fast and group pressure forces me to use many strategies to keep up conversations with native speakers so as to be totally immersed in the culture."(Andy)

"Group pressure inspires me to look for more chances for myself to communicate." (Lee)

In other words, group presence accelerated the improvement of their strategic competence. Under the influence of group pressure, the other members were also encouraged to participate actively in communication, which could be exemplified by the group's wider and fuller use of different communication strategies in social and transactional communication. Just as Jessica said in the interview, "on some occasions, when I see others speaking English much and well, it will push me to speak more. I have to talk more by some means, or I will fall behind others."

On the other hand, the negative group influence on selection of communication strategies is also apparent. First, it was hard for a group of Chinese visiting scholars to keep talking with each other in English when there were no native speakers or international students among them. Since the language proficiency of Chinese language teachers was different, those who had small vocabulary and couldn't express them fluently might feel ashamed or awkward in front of their colleagues. Ron ever recommended speaking English among the group, but it was carried out only for one day. In the interview with language teachers, some explained why they didn't speak English in the group.

"I can't stand someone's not-so-good pronunciation." (Jessica)

"Some of us are too talkative, and I can hardly join in the conversation. "(Carol)

"It's absurd that a group of Chinese people speak English."(Kate)

"I don't want to show my weakness in public."(Martin)

So it's no wonder why English conversation can't be on among the group. Here group dynamics exerted its strong negative influence. Second, in group activities, when some language teachers were too talkative or pushy to grasp the chance of speaking, some others tended to keep silence. This could be exemplified by some language teachers' choice of avoidance strategy and generalization in classroom and social communication. When asked why they chose to speak less, some language teachers expounded,

"It's impolite to talk too much in public." (Ron)

"The class time is limited, and I don't want to waste others' time by speaking too much." (Kate)

"If one sentence can express your idea clearly, why do you bother to explain too much? It will make others bored. "(Martin)

"I'd like to communicate with native speakers privately. Talking too much in public makes you unwelcome to the group." (Carol)

Therefore, the fear of being a black sheep in the group forced some language teachers to choose some certain strategies. 


\section{Conclusion}

All in all, language teachers do improve their strategic competence during their visiting study in the United States. Whether they are conscious or not, they have to resort to some communication strategies when linguistic problems or communicative barriers arise. Language proficiency, personality and group dynamics influence language teachers' selection of communication strategies.

\section{Acknowledgements}

Fund Project: “A study on research ability of English teachers in high school”(TER2017-009).

\section{References}

[1] Tarone, E. Some Thoughts on the Notion of Communication Strategy. TESOL Quarterly, 1981,15 (3):285-295.

[2] Bialystok, E. Communication Strategies: A Psychological Analysis of Second Language Use[M]. Cambridge: Basil Blackwell, 1990.

[3] LUO, X. J. The Connotation and Development of Junior Middle School Students' Oral English Communicative Competence-Based on National English Curriculum Standards of Compulsory Education (2011 Edition) [J]. Curriculum, Teaching Material and Method, 2012, 32(12): 47-50. (In Chinese)

[4] Brown, H. D. Principles of Language Learning and Teaching ( $5^{\text {th }}$ edition)[M]. New York: PEARSON Longman, 2007.

[5] Tarone, E. Conscious communication strategies in interlanguage[A]. In H.D. Brown, C. A. Yorio and R. C. Crymes (Eds.). On TESOL '77[C]. Washington, D.C.: TESOL,1977.

[6] Backstrom, L., Huttenlocher, D., Kleinberg, J. and Lan, X. "Group formation in large social networks". Proceedings of the 12th ACM SIGKDD international conference on Knowledge discovery and data mining-KDD, 2006:44.

[7] Pinto, I. R., Marques, J. M. and Abrams D. Membership status and subjective group dynamics: Who triggers the black sheep effect? [J]. Journal of Personality and Social Psychology. 2010, 99 (1): 107-119 